Bryant University

Bryant Digital Repository

English and Cultural Studies Journal Articles

English and Cultural Studies Faculty

Publications and Research

Winter 2-8-2018

\title{
Throwing our Voices: Ventriloquism as New Media Activism
}

Amber Day

Bryant University, aday@bryant.edu

Follow this and additional works at: https://digitalcommons.bryant.edu/eng_jou

Part of the Other Arts and Humanities Commons, and the Other Film and Media Studies Commons

\section{Recommended Citation}

Day, Amber, "Throwing our Voices: Ventriloquism as New Media Activism" (2018). English and Cultural Studies Journal Articles. Paper 85.

https://digitalcommons.bryant.edu/eng_jou/85

This Article is brought to you for free and open access by the English and Cultural Studies Faculty Publications and Research at Bryant Digital Repository. It has been accepted for inclusion in English and Cultural Studies Journal Articles by an authorized administrator of Bryant Digital Repository. For more information, please contact dcommons@bryant.edu. 


\section{Throwing Our Voices: Ventriloquism as New Media Activism}

Media, Culture, and Society 40.5, 2018.

In the fall of 2010, Chevron released an ad campaign designed to respond to consumer worries about the conduct of oil companies. Each ad depicted “customers” voicing rather nonspecific concerns about oil companies, answered by the "We Agree” slogan and information about something positive the company is doing in particular communities. Just before the campaign's official roll-out, the anti-corporate activist group known as the Yes Men produced a series of sophisticated parody ads that spoke in more detail about the damage the company has done in specific countries. Designed to be mistaken for the real, the dummy campaign was distributed with a fake press release purporting to be from Chevron. It was indeed picked up by the press, followed by a cascade of confused articles quoting alternately from the company's real retraction and a subsequent fake retraction. The Yes Men succeeded in temporarily "throwing their voice" into the body of the Chevron corporation, using a savvy form of ventriloquism as a means of directing the public conversation. Although it is normally the powerful (like large corporations) who are heard in public life, often speaking both for themselves and others, the tactic of ventriloquism temporarily reverses that flow. The case study provides a compelling example of a method of capitalizing on the democratic potential of new media, wielding parody and play as a weapon of the crowd.

Unfortunately, discussions about digital media often become cartoonishly deterministic. As we ponder the impact new technologies will have on our lives, the temptation is to speak as if the technology will single-handedly change who we are as people. Predictions abound about 
how new media will make us smarter or dumber, happier or more harried, and how they present radical challenges to our social and political order. As Nancy Baym puts it, “determinism can be recognized from its causal construction. The media are positioned as cause, the people are positioned as changed” $(2010,151)$. This determinism routinely surfaces in proclamations about the democratizing effects of new media, the assumption being that the technology itself levels media playing fields, giving power to the people and bestowing a ready instrument of amplification to nearly anyone who wants one (an example being when Time Magazine named "You” the person of the year in 2006 (Grossman, 2006). As Astra Taylor points out, however, the way in which digital media are actually operating are very similar to the ways in which older media operated. Networked technologies make:

commercialism less visible and more pervasive. The internet does not close the distance between hits and flops, stars and the rest of us, but rather magnifies the gap, eroding the middle space between the very popular and virtually unknown. And there is no guarantee that the lucky few who find success in the winner-take-all economy online are more diverse, authentic, or compelling than those who succeeded under the old system. $(2014,7)$

Or, as Robert McChesney frames it, digital technologies have no superpowers over the defining forces of capitalism, as the "democratization of the Internet is integrally related to the democratization of the political economy” (2013, 22). Indeed, real power continues to reside with wealthy media conglomerates.

Though there may be a proliferation of speech, much of the time there is still a massive imbalance in who is actually heard. Nick Couldry argues that we are in fact "experiencing a contemporary crisis of voice, across political, economic and cultural domains, that has been growing for at least three decades” $(2010,1)$. He explains that in countries like the UK and the USA, “voice is persistently offered, but in important respects denied or rendered illusory; and at 
the root of these contradictions is a doctrine (neo-liberalism) that denies voice matters” (1). The reigning neo-liberal world-view imposes an economic or market logic on all aspects of life, including the political and the social, diminishing the importance of political voice. Couldry concludes that "it is the interactive dimension of voice that is crucial: technological forms enable, but cannot guarantee, this. Voices may multiply but democracy still fail” (144). Indeed, we can speak all we want, but if no one is listening, such speech matters little.

Within the public sphere, the voices that are heard loudly are those of corporations able to pay for message saturation via advertising and PR. That said, the accessibility of digital technologies does provide opportunities for creative play with professional formats, allowing for easily produced parody, pranking, and critique. The activist campaign examined here provides an example of the less powerful successfully using new technologies to speak out. Capitalizing on the volume and reach of corporate speech, The Yes Men use a technique I will refer to as “ventriloquism” as a means of temporarily bending the microphone toward an alternative voice. While it is misleading to speak of new media as inherently democratizing, I do think it is productive to examine the instances in which it is used strategically as such a force. This particular case study demonstrates that poaching on the voice of the powerful can be a valuable tool for both affecting the wider public conversation and for building communities, laying the groundwork for future actions.

\section{The Campaign}

The Yes Men are an activist group fronted by just two men that has gained notoriety for their spectacular attempts to direct public discussion about corporate responsibility and 
neoliberal economics. Through the use of parody websites and the like, they have managed to repeatedly be invited to conferences and news interviews as spokespeople for organizations to which they don't actually belong. They then pretend to earnestly speak on behalf of the company, voicing either what they believe to be the genuine craven motivations of the organization or issuing the statements they fervently wish these companies would make.

Tipped off ahead of time about the details of the Chevron "We Agree" campaign and its scheduled release, The Yes Men succeeded in perfectly reproducing its iconography. In both versions, close-ups of individual faces are juxtaposed next to a gray panel emblazoned with a pithily expressed concern in stark black text. The words "We Agree" are stamped underneath in red. Only, the activists' version includes the faces of people from countries where the company is embroiled in disputes rather than those of models, and in the place of vague platitudes, they include far more specific demands. The official ads include text such as "oil companies should put their profits to good use” or “oil companies need to get real,” (Packer) accompanied by rosy assurances that profits are being invested in jobs and growth. In contrast, one of the activist versions reads: “oil companies should clean up their messes,” (“Chevron’s \$80 Million,” 2010) along with details about specific environmental and human rights abuses the company is accused of and the pledge to do better. The small print of one hacked ad reads: "For decades, oil companies like ours have worked in disadvantaged areas, influencing policy in order to do there what we can't do at home. It's time this changed. People in Ecuador, Nigeria, the Gulf of Mexico, Richmond, and elsewhere have a right to a clean and healthy environment too" (“Chevron’s \$80 Million,” 2010). The accompanying fake press release explains that the new campaign is “aimed at showing Chevron as a 'real people' corporation, and admitting to abuses that companies usually try to hide” (Radical Chevron Ad, 2010). 
Chevron was not amused, issuing a tersely worded response with a request that media inquiries be directed to their public relations division. The Yes Men, on the other hand, issued a far meatier fake retraction on Chevron's behalf, which was once more confused with the real by some news outlets whose attention had been piqued (Clendaniel, 2010). The language of the retraction was such a smooth parody of public-relations-ese that it seemed just plausible enough. However, this chattier version was smattered with quotations from fictitious Chevron officials, and included more details on specific legal disputes, as well as supposed reasons why Chevron was in the right, including “we are not obliged to abide by decisions that Ecuadorian judges make or do not make. This is because we have binding agreements with the Ecuadorian Government exempting us from any liabilities whatsoever, granted in exchange for a \$40 million cleanup of some wells by Texaco in the 1990s” (Clendaniel). In other words, the Yes Men's version spoke what they believed to be the real thinking of Chevron executives. This strategy handily assured that rather than talking about the hazy good vibes stuff of the campaign, subsequent media reports on the hoax were centered on the details of these real cases (Elliott, 2010).

\section{Ventriloquism}

Ultimately, what the Yes Men succeeded in doing was using ventriloquism as a way of poaching on Chevron's powerful public voice. Steven Connor, author of a cultural history on ventriloquism, defines the practice as "making voices appear to issue from elsewhere than their source,” (2000, 13-14) which he traces through its association with demonic possession to the contemporary technique of stage performance with a dummy. Francois Coonen further adapts 
the term to refer to the variety of forms of agency involved in any act of communication (2012, 4). He explains that people often speak on behalf of organizations, policies, ideologies, etc., but that "if I ventriloquize an ideology, whether consciously or unconsciously, it is also this ideology that impels me to defend positions to which I feel attached. The effects of ventriloquism therefore are bidirectional and mark an oscillation/vacillation” (2012, 6). Though he offers an intriguing model of communication, Coonen treats ventriloquism metaphorically, and does not speak to the power dynamic at play in speaking on behalf of another. In this particular case, I am focused on how The Yes Men forcibly threw their own voices into the body of the corporation as a means of temporarily directing the public conversation.

What is less readily apparent because we are so accustomed to it, is the fact that Chevron was the first ventriloquist. Chevron wanted to appear to be having a discussion with the public so they created dummies - played by actors and models - to stand in for various members of the public, for whom they wrote scripted lines. Notably, this is what most advertising does, allowing a company to speak through the bodies of seemingly satisfied customers. Advertisers seek to do such a good job of telling us what our and our neighbors’ desires are that we accept the sentiments as our own, ideally feeling as if the company has managed to voice what we were already thinking. In this case, the ventriloquism happens to be noticeable as Chevron was especially invested in creating the appearance of dialogue. The overall tag line for the campaign is the chummy sentiment, "You might be surprised to see how many things we can agree on" (https://www.chevron.com/weagree/australia/, 2010) and the organizing premise is that the company is responding to the real concerns of citizens like you. However, much like one of those folksy town-hall meetings staged by politicians, the concerns voiced are only those for which they have prepared answers. 
In this case, The Yes Men blew Chevron's cover by usurping their powerful voice. Nevertheless, the company stubbornly tried to maintain the appearance of conversation. In their official response to the hoax, they wrote "Chevron's new advertising campaign is meant to identify and highlight common ground on key energy issues so we can move forward safely, intelligently and collaboratively. Unfortunately, there are some who are not interested in engaging in a constructive dialogue, and instead have resorted to rhetoric and stunts” (http://www.good.is/post/chevron-gets-the-yes-men-treatment, 2010). They went on, “Today, activist groups have attempted to interrupt the conversation by issuing a fake press release and establishing a counterfeit website, which are not affiliated with Chevron” (my emphasis). The attempt was to paint the activists as saboteurs bent on disrupting the honest discussion taking place, though any such discussion was clearly fictional. Or maybe Chevron did think of what they were doing as dialogic, only they have become used to scripting both sides of the conversation - a dialogue between ventriloquist and dummy.

We are so accustomed to advertising speaking for us - voicing our supposed fears, desires, and unmet cravings - that it is almost invisible. However, corporations certainly take notice when they are spoken for, as it is an unusual (and unwelcome) occurrence. In this case, The Yes Men, a relatively powerless handful of activists, seized on ventriloquism as what James C. Scott calls a "weapon of the weak," or what Michel deCerteau refers to as a "tactic." In de Certeau's description, tactics are used to poach on the territory of the powerful by those who do not have a base from which to operate. A tactic “insinuates itself into the other's place fragmentarily, without taking it over entirely” (1984, xix). This is a good description of how a group like The Yes Men has risen to near cult status amongst activist groups. They routinely seize opportunities to speak on behalf of their targets. Most famously, for instance, the group 
appeared on the BBC as representatives of Dow Chemical and announced that the company was finally taking responsibility for the plant explosion in Bhopal, India 20 years prior, and that they had set aside money for compensating victims and cleaning up the site. When the company was forced to issue a retraction saying that they were doing nothing of the kind, a flurry of news reports brought the all but forgotten issue back into public discussion. The Yes Men have a long history of tactically insinuating themselves into spaces reserved for legitimate power by temporarily hijacking information flows.

\section{Culture Jamming}

By mimicking Chevron’s own advertisements, the Yes Men are building on the wider tradition of “culture jamming,” which broadly refers to the practice of repurposing or deconstructing media texts, or of using mass culture against itself. More specifically, the term is most often employed to refer to the practice of "subvertising” or the parodying of existing advertisements and the related project of physically altering billboards to communicate a critical message about the company in question. The philosophy underlying the practice tends to be the belief that corporations have an outsize voice in the public sphere and that culture jamming offers an opportunity for speaking back. As Naomi Klein puts it, culture jammers are united in the feeling that "free speech is meaningless if the commercial cacophony has risen to the point that no one can hear you” (Klein, 2002, 284). The intent is to raise a chorus of opposing voices.

Advertising parody has existed as long as there has been advertising. The more politicized version common in culture jamming was particularly popular in the 1990s and 2000s, but attracted some critique, often from those theoretically sympathetic to the underlying 
philosophy. Some of the major criticisms are that culture jamming is not always easily deciphered, that its critique may be obscured, or that its style can be easily re-absorbed into the world of advertising. Others have complained that culture jamming does not offer solutions or even tangible alternatives. Rather, as Christine Harold asserts, it simply scolds us for giving in to consumer pleasures. She points to the magazine Adbusters and some of its more famous antiads targeting cigarette and alcohol companies. In her opinion, the magazine puts itself in the disempowered position of only being able to react, as "the nay-sayer is, in essence, yoked in a dialectic tug-of-war with the rhetoric it negates” $(2007,57)$, while its only advice to us as consumers is to "avert our eyes from the mesmerizing Spectacle" (53).

An example such as the Yes Men’s Chevron ads, however, makes use of culture jamming techniques in a far more targeted way. It too uses the style and language of advertising against itself, but the critique here is aimed at specific business practices rather than diffusely at a company or industry as a whole. These parody ads also do gesture to specific demands, though the words are put into the mouth of the corporation, as they imagine Chevron coming up with the correctives themselves. It is culture jamming savvily taken up a notch. At first duping, and then inviting incredulous examination, the critique is obvious upon secondary examination. It is packaged so as to be accessible to onlookers, both those in the media and on the sidelines, and it ensures that the specific demands made of the corporation almost necessarily must be repeated in any coverage. It also provides the hook for reporters. A vandalized billboard is hardly news for any but the most local of newspapers. A hijacked advertising campaign or press conference, in contrast, often becomes a tantalizing story. 


\section{Inviting Engagement}

The objective seems multi-fold. The most immediate one is to generate bad publicity for Chevron, drawing attention to their environmental and human rights abuses, along with the company’s brazen attempt at greenwashing its image. Perhaps more importantly, one of the primary strengths of ironic activism such as this is its ability to get onlookers engaged and to create the feeling of community in opposition. As Linda Hutcheon defines it, irony is characterized by the simultaneous existence of both a said and an unsaid meaning. For interpreters to get the irony, they must choose to read both, actively participating in the meaningmaking process. Ironic activism speaks to people who already share similar opinions and/or senses of humor and attempts to parlay that into a sense of community, making people aware of all those others who feel the same way. Ideally, this kind of affirmation and reinforcement works to translate diffusely shared feelings into actively politicized collectives. In this campaign, The Yes Men sent out a slew of press releases to their large listserve, not simply to amuse their fans but to enlist their participation. They announced that they were turning the campaign into a contest. Under the tag-line “Chevron Thinks We’re Stupid” (“Chevron’s \$80 Million”) they urged people to create their own posters, videos, or altered billboards to let Chevron know what they were really thinking. They provided design resources like the Chevron ads’ font, and a do-it-yourself billboard alteration kit, making it easy for lay-people to get involved. Later they announced a wheat-paste contest, challenging fans to print out ads in the contest gallery and publicly post them as creatively as possible. The attempt, as with much of the Yes Men’s work was not just to amplify their critique of Chevron, but to make as many people as possible invest in the campaign. 
The salience of this community building function is often overlooked in discussion of activist accomplishments, but is enormously important. While the vast majority of individual marches, protests, and pranks do not meet with success if measured as instant political change, they may still galvanize support, recruit new volunteers, fuel belief in the possibility of change, and/or slowly nudge public opinion. Conversely, as Michael Warner points out, if the idea of addressing a public capable of comprehension and action is unimaginable by those in marginal positions or those distributed across political systems, the result is a blockage of activity and optimism, "a disintegration of politics toward isolation, frustration, anomie, forgetfulness" (2002, 70). In this case, for anyone (politically active or not) who is even vaguely uncomfortable with the outsize power of corporations in contemporary life, their sheer monolithicness can feel insurmountable, as if it would be useless to oppose a particular corporation's behavior since it is seemingly impossible to even register a complaint as one powerless individual. What the Yes Men do provides a potential sense of pleasure and satisfaction for anyone who has ever wished to speak back to large corporations, as they succeed in doing so in a spectacular manner. They remind us of others who share similar sentiments about corporate misdeeds and they provide the platform for everyone to join the fun, adding their own voice to the chorus of consumer critique. As Ian Reilly explains of another Yes Men stunt, the group’s effort is consistently focused on bridging “the divide between consciousness-raising and political/civic participation” (2013, 1246). In this case, it is Do-It-Yourself activism as simple as composing some witty ad-copy.

As Stephen Duncombe argues, we live in a time when neo-liberal corporate capitalism reigns virtually uncontested. As he puts it, this “dominant system dominates not because people agree with it; it rules because we are convinced there is no alternative” (theopenutopia.org, 2014). While The Yes Men certainly do not provide the blueprints for another sort of system, 
they do encourage public discussion of the current one. Their work prompts what Duncombe and Henry Jenkins elsewhere refer to as “critical utopianism” (2008). By presenting us with a version of our world that doesn’t actually exist, one in which a company like Chevron would call public attention to their misdeeds and pledge to change, they encourage us to imagine such a world and to ask ourselves why it does not exist or what it would take to bring it into being. Critical utopianism invites belief that something else might be possible, or that it ought to be possible.

According to Warner, a public comes into being through attention to, citation of, or dialogue with shared media. When someone aims to speak to others (through oratory, print, artwork, etc), s/he “says not only 'Let a public exist' but "Let it have this character, speak this way, see the world in this way.' It then goes in search of confirmation that such a public exists, with greater or lesser success - success being further attempts to cite, circulate, and realize the world understanding it articulates” $(2002,114)$. The aim of much activism is similarly to find others who will sympathize with the group’s views and will spur continued circulation of its critique. Kate Lacey compellingly argues why mediated listening is an important civic activity $(2011,6)$, though, in this case, the Yes Men invite those who appreciate their overall message to also take a turn as ventriloquists (and to expose the corporate ventriloquists as such). They encourage us all to be the speakers rather than the spoken for. It is an exhortation to not accept voicelessness, but to instead enter the conversation through whatever means are available. That involves both taking that leap of faith that one’s actions can have an impact, as well as the experience of finding pleasure or purpose in action. 


\section{New Media and Democracy}

This case study provides an example of new media successfully used for populist aims. It is important to note, however, that this response to Chevron's ad campaign did not develop spontaneously. It was a highly coordinated, centralized attack. A more unstructured outpouring of user-generated content receiving as much attention would be far more unlikely. Uncritical discussions of the democratic potential of new media tend to gloss over these realities. Here Matt Sienkiewicz provides a helpful explanatory model in his discussion of citizen journalism in the Syrian civil war. As he explains, when commentators discuss the use of new media and user generated content, they frequently conceptualize a "two-tier” system in which amateur producers expose new truths followed by mainstream media amplification. He argues, however, that such a system is often problematic. Rather, in complex situations, like the Syrian civil war, when there is a massive amount of information being pushed forward, a middle "interpreter tier" becomes essential for mediating between citizen journalists and mainstream outlets (2014, 692). The third tier proved crucial in the Syrian situation and presumably would be in other complex situations for "the sheer mass of user-generated material to possibly be made legible and coherent" (695). I would argue that there is a similar dynamic at work in citizen agitation/activism. In this particular case, a semi-professional network of activists coordinated and disseminated the campaign, pitching the story to the press while also attracting more participants. This layer of centralization helps ensure that the efforts expended are more likely to be amplified by the media, and that the message disseminated will be coherent. It is an example of the democratic potentialities of new media, but speaks to the need for calculatedly strategic action.

While digital technologies are not inherently democratic, they do have great potential for strategic use. In this instance, a handful of savvy activists were able to temporarily assume 
Chevron's considerable stature and authority, drowning out the company's carefully scripted voice with their own. While Chevron has the budget to dominate the discourse about its affairs in television commercials and print ads, the Web is more unpredictable. The advantage is certainly still Chevron's, but user-generated images compete for audience attention, sometimes creating an unanticipated melding. To date, a Google image search for "Chevron We Agree," results in a seamless mix of the real ads and the parody ads, meaning, as far as the campaign's web presence is concerned, that the two competing voices have almost entirely become one. That is not inconsequential.

The Yes Men often achieve tangible results. Although I have compared their techniques to the "tactics" described by de Certeau, there is a major difference in scale between the two. While de Certeau has been criticized for romanticizing the "subversive" behavior of the powerless, making it seem as if relatively inconsequential behavior is doing something to address power imbalances, The Yes Men's tactics are strategically designed to inflict as much damage as possible. Rather than gently pushing at the margins, this activist group hopes to draw international attention. And, indeed, they are often successful. That said, we should not exaggerate the impact of these stunts. At the end of the day, Chevron is still massively more powerful than the activists, with infinitely more money at their disposal to continue shoring up their brand. Nevertheless, The Yes Men, drawing primarily on time, organization, and creativity were able to inflict fairly significant harm to a multi-million dollar ad campaign. Perhaps more importantly, most activism aims to effect the public conversation, changing the terms on which we discuss - say - the responsibilities of oil companies, which this campaign went a fair way towards doing by drawing attention to the subject and opening debate on their own terms. 
In an era when we see money, power, and speech cohering to an enormous degree, playing with voice seems a central strategy for any disempowered constituency. Indeed, it may be the only strategy that matters: to be heard. The proliferation of platforms for speech in the contemporary media landscape create the impression that there are many opportunities to make oneself heard. Most of these opportunities are illusory. However, as the Yes Men demonstrate, it is sometimes possible to create one's own. Rather than waiting for the meager crumbs of attention otherwise doled out to activists, this group poaches on the ready speech afforded to the powerful. Doing so, in this instance, temporarily upended hierarchies of power. To be sure, Chevron remained at the center of discussion, but in a narrative not of their own design, while the activists conducted the conversation. Ventriloquism as tactic allowed the Yes Men to position themselves as the speakers rather than the spoken-for.

The case study demonstrates that ventriloquism is a potentially powerful form of manipulation. Like other forms of parody and pranking, it captures attention, gets people engaged, and can potentially shift the terms of debate. It also seems a particularly apt form of anti-corporate activism, given that corporations have such an outsize voice in the public sphere. The more powerful the voice, the more difficult it can be to rebut (or to truly dialogue with despite Chevron’s protestations to the contrary). But successfully hijacking and speaking through that voice offers the possibility of at least temporarily effecting the public discussion. 


\section{Works Cited}

Baym, Nancy K. Personal Connections in the Digital Age. Cambridge, MA: Polity Press, 2010.

“Chevron’s \$80 Million Ad Campaign Gets Flushed.” Yeslab.org, 19 October, 2010, http://yeslab.org/project/chevron.

Clendaniel, Morgan “Chevron Pranked by the Yes Men.” Good Magazine. 20 October, 2010. http://magazine.good.is/articles/chevron-gets-the-yes-men-treatment

Connor, Steven. Dumbstruck: A Cultural History of Ventriloquism. Oxford: Oxford University Press, 2000.

Coonen, Francois. "Communication Theory at the Center: Ventriloquism and Communicative Constitution of Reality,” Journal of Communication 62, 2012, pp. 1-20.

Couldry, Nick. Why Voice Matters, Culture and Politics after Neoliberalism. Sage, 2010. deCerteau, Michel. The Practice of Everyday Life. Trans. Steven Rendall. Berkeley: University of California Press, 1984.

Duncombe, Stephen. “Introduction: Open Utopia” Open Utopia. n.d. Web. 14 August, 2014.

Elliott, Stuart. "Pranksters Lampoon Chevron Ad Campaign.” The New York Times. 18 October, 2010.

Grossman, Lev. “You - Yes, You - Are TIME’s Person of the Year.” Time Magazine. 25 
December, 2006.

Harold, Christine. Ourspace: Resisting the Corporate Control of Culture. Minneapolis: University of Minnesota Press, 2007.

Jenkins, Henry, and Stephen Duncombe. "Politics in the Age of YouTube.” Electronic Journal of Communication. 18.2-4, 2008.

Hutcheon, Linda. Irony's Edge: The Theory and Politics of Irony. London: Routledge, 1994.

Klein, Naomi. No Logo: No Space No Choice No Jobs. New York: Picador, 2002.

Lacey, Kate. "Listening Overlooked: An Audit of Listening as a Category in the Public Sphere.” Javnost - The Public, Vol. 18, No. 4, 2011, pp. 5-20.

McChesney, Robert W. Digital Disconnect: How Capitalism is Turning the Internet Against Democracy. New York; London: The New Press, 2013.

Packer, Jesse. “Advertising Samples.” Coroflot, http://www.coroflot.com/packer/advertisingsamples?school_name=Pratt+Institute\&specialty=9\&. Accessed 14 June, 2017.

“Radical Chevron Ad Campaign Highlights Industry Problems” Press Release. Oct. 18, 2010

Reilly, Ian. "From Critique to Mobilization: The Yes Men and the Utopian Politics of Satirical Fake News.” International Journal of Communication. 7, 2013.

Sienkiewicz, Matt. "Start Making Sense: A Three Tier Approach to Citizen Journalism.” Media, 
Culture, and Society. Vol. 36(5), 2014.

Scott, James C. Domination and the Arts of Resistance: Hidden Transcripts. New Haven, Conn.: Yale University press, 1990.

Taylor, Astra. The People's Platform: Taking Back Power and Culture in the Digital Age. New York: Metropolitan Books, 2014.

Warner, Michael. Publics and Counterpublics. New York: Zone Books, 2002.

“We Agree. Do You?” Chevron Australia, https://www.chevron.com/weagree/australia/. Accessed 14 June, 2017. 